\title{
A DECISION APPROACH FOR PRIORITIZING FACTORS AFFECTING VESSEL CREW SATISFACTION USING ANALYTIC HIERARCHY PROCESS
}

\begin{abstract}
This study aims to examine factors affecting the satisfaction of vessel crew in a specific line company in terms of organizational conditions, work environment, economic conditions, vessel properties, and living conditions. In order to determine which factor affects the employee satisfaction more, the Analytic Hierarchy Process is used and the criteria are prioritized based on the pairwise comparisons of the employees working in the vessels of this line company. Due to different characteristics of vessels and also varying scope of the work performing by different job titles, besides the whole results, the findings are interpreted based on the vessel types and the job titles. The shipping industry is a very specific industry which requires very special trainings, certificates, and profession to be employed in. Employee qualifications, employee errors in shipping accidents, employee engagement, and employability indicators are investigated by using different approaches, and the relationship between organizational commitment and job satisfaction is examined in a few studies. Yet, there is a lack of the literature focuses solely on factors affecting the employee satisfaction in this industry. Among several reasons of this lack, the nature of the job which makes harder to collect data from vessel crew, the complexity and scope of the problem which requires more time and effort to model, the lack of academic and practical expertise both on the shipping industry and decision making discipline can be listed.
\end{abstract}

Keywords: Analytic Hierarchy Process, shipping industry, vessel crew, satisfaction

\section{Introduction}

In shipping industry, the most important problems preventing people to work on the vessels are being away from their families and living with the same people on a restricted area for months. Besides the monetary advantages of being employed on the vessels as a member of crew, there are several factors affecting the physical and mental health of the employees. In this study, factors affecting the satisfaction of vessel crew in a specific line company are prioritized by using Analytic Hierarchy Process (AHP). By using this decision framework, the management of this line company enables to observe the most important factors affecting the employee satisfaction and utilize this tool for offering them the necessary options for improving their satisfaction level. This framework can also be used by other line companies.

\section{Literature Review}

There is a lack of literature on vessel crew satisfaction. Even the range of retention (de Silva et al., 2011; Caesar et al., 2015) and employee engagement (Bhattacharya, 2015) are analyzed, the satisfaction of vessel crew is not a primary concern of the researchers in this area. The relationship between organizational climate, organizational commitment, and satisfaction is analyzed by using a Hierarchical Linear Model in a generalized form without exploring the factors related to each item (Hou and Wu, 2014). On the other hand, examining the relationship between some leading factors and job satisfaction by using Structural Equation Modeling is very common in the literature and one of the studies representing the satisfaction of Chinese seafarers ( $\mathrm{Li}$ et al., 2014) is utilized for determining the factors in this study.

\section{Decision Model}

Inevitably the problem on hand is a multi-criteria decision making problem where evaluation criteria are several, conflicting, weighted, and incommensurable. As the problem can be modeled as a hierarchy, AHP, one of the most widely used multi-criteria decision method, is used. 
The criteria sets which are determined to prioritize factors affecting the employee satisfaction are organizational conditions, work environment, economic conditions, vessel properties, and living conditions. The sub criteria of $i$ ) organizational conditions are organizational attachment, career opportunities, and continuity of employment; ii) working conditions are work load, route, staying in port, and duration of employment contract; iii) economic conditions are salary amount, salary period, and exchange rate; $i v)$ vessel properties are age, maintenance status, and type of the cargo; v) living conditions are cabin conditions, lounge conditions, gym conditions, and quality of meals.

\section{Research Design/Methodology}

To prioritize the factors affecting vessel crew satisfaction, AHP is used. Factors are determined based on the literature review and expert views. The analysis is performed by using Super Decisions software. If there is an inconsistency for pairwise comparisons, the related expert is asked to perform the pairwise comparisons again to reduce the inconsistency.

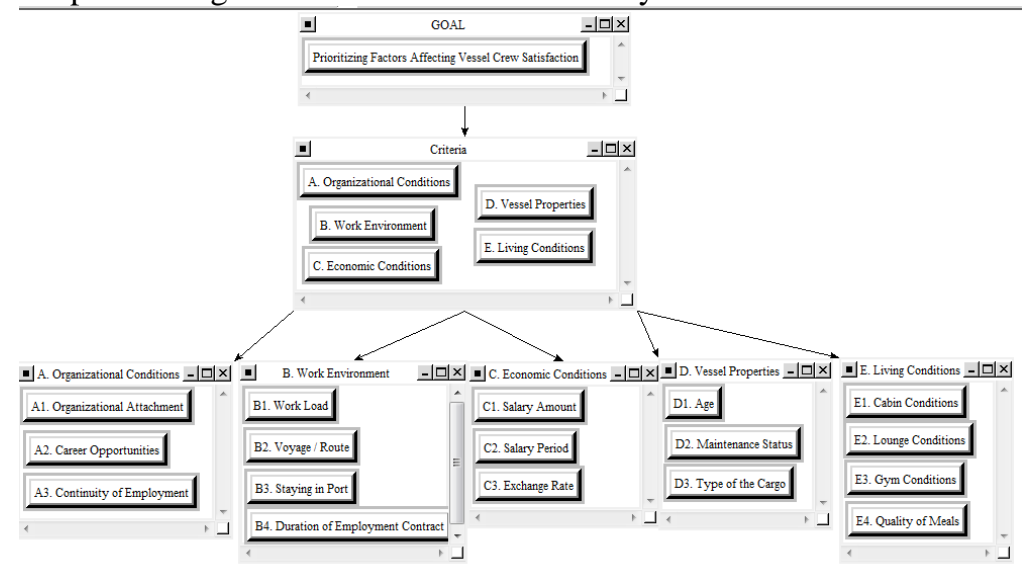

\section{Data/Model Analysis}

This paper will present the results of an ongoing research that is not yet complete.

\section{Conclusions}

AHP is used to prioritize the factors affecting vessel crew satisfaction. This study provides a useful and practical tool to examine which factors have considerably higher effects on employee satisfaction and the proposed decision framework can be used by al companies in shipping industry. Data collection is still continuing and after the required analysis, prioritized factors will be obtained.

\section{Key References}

Hou, F.-I., Wu, Y.-L. (2014). Using the hierarchical linear model to construct organizational climate, organizational commitment, and work satisfaction relationships of freight forwarder shipping companies, The 12th International Conference on Advances in Mobile Computing and Multimedia (MoMM 2014), Kaohsiung, Taiwan, 8-10 December.

Bhattacharya, Y. (2015). Employee engagement in the shipping industry: a study of engagement among Indian officers, WMU Journal of Maritime Affairs, 14(2), 267-292.

Li, K.X., Yin, J., Luo, M., Wang, J. (2014). Leading factors in job satisfaction of Chinese Seafarers, International Journal of Shipping and Transport Logistics, 6(6), 680-693.

Caesar, L.D., Cahoon, S., Fei, J. (2015). Exploring the range of retention issues for seafarers in global shipping: opportunities for further research, WMU Journal of Maritime Affairs, 14, 141-157.

de Silva, R., Stanton, P., Stanton, J. (2011). Determinants of Indian sub-continent officer-seafarer retention in the shipping industry, Maritime Policy \& Management, 38(6), 633-644. 